\title{
TÓPICOS PARA UMA LEITURA DE O SOFISTA
}

Jayme Paviani*

SíNTESE - Indicação de tópicos do prólogo de o Sofista considerados relevantes, sob o ponto de vista propedêutico, para o estudo do diálogo na perspectiva do processo diairético. Observações sobre as implicações entre o método, os temas e a estrutura do diálogo.

PALAVRAS-CHAVE - dialética, diairesis, método filosófico.
ABSTRACT - This article indicates topics of the Sophist, which are significant, while preliminary perspective, for the dialogue's study in diairesis process. The article makes still some observations about the existent implications in the dialogue among method, themes and structure.

KEY-WORDS - dialectic, diairesis, philosophic method.

As vias de acesso aos grandes temas e ao método dialético de Platão em o Sofista são numerosas e difíceis. Trata-se de um diálogo que apresenta questões complexas, cujo entendimento divide os comentaristas. O objetivo deste estudo, sem deixar de lado essas questões nucleares da filosofia, procura examinar aspectos metódicos de sua articulação e desenvolvimento. Certamente o Sofista é um diálogo onde se pode examinar aspectos básicos da dialética platônica, principalmente se for levada em conta a hipótese de que nesse texto a refutação, elenchos, introduzida como uma forma de purificação (cf. sexta definição do sofista, 226-233), é substituída pelo processo da divisão, diairesis, de um único gênero numa multiplicidade de coisas distintas, o que implica uma unificação, synagogê, da multiplicidade numa Idéia ou gênero. Esta hipótese, por sua vez, abre a possibilidade de investigar os processos metódicos dos diálogos de Platão numa perspectiva mais abrangente. Por ora, algumas observações preliminares têm a função de preparar a leitura e o comentário de momentos relevantes do texto.

Platão, em seus primeiros diálogos, procura entender aquilo que é. Exemplo disso são as questões: o que é a justiça, a beleza, a virtude. Em o Sofista, a pergunta "o que é" transforma-se na pergunta "o que é o ser". Há um deslocamento da simples constatação para uma reflexão sobre o que é, sobre o significado do ser. Diante das dificuldades que a questão oferece, o personagem central, o Es-

* Coordenador do Curso de Pós-Graduação em Filosofia, Instituto de Filosofia e Ciências Humanas da PUCRS. 
trangeiro de Eléia, indaga: "O que quereis significar quando pronunciais a palavra ser? Evidentemente, são coisas que há muito vos são familiares. Nós mesmos, até agora, pensávamos compreendê-las, e, hoje, estamos confusos" (244a). Esta citação do texto, apresentado em forma de monólogo com interlocutor, portanto, tipificando um diálogo "fraco", onde um expõe e outro faz perguntas apenas para elucidar a questão, pode ser resumida nas seguintes perguntas: o que se entende por este vocábulo "ser" nas proposições em que ele é dito? Se o ser nos é "familiar", e nós todos pensávamos compreendê-lo, por que, agora, nos parece confuso? A segunda pergunta, a que indaga sobre os motivos do porquê o que era compreensivo já não o é mais, depende da primeira, a que interroga sobre o sentido do termo ser.

Platão mostra que o ser tem uma essência (ousia) que corresponde àquilo que é o ser. Desde sempre o ser (essência) nos é familiar, porém quando nos pomos a refletir sobre sua existência ele se torna confuso. Ser e o fato de ser são aspectos diferentes. Perguntar o que é, pela essência (ousia) como no Fedro (237c) ou pela essência do belo, da virtude, da justiça, respectivamente no Banquete, no Menon, na República e em outros diálogos, é perguntar pela Idéia, por sua inteligibilidade. Porém, a Idéia ou Forma, enquanto ser, enquanto a priori, próxima ao homem, "familiar" através de reminiscência, antes de ser investigada, não é conhecida. Não se sabe ainda o que é o ser quando se diz que algo é.

O Sofista instaura a reflexão sobre que é o ser. Para dizer o que é o ser, procura distingui-lo do parecer. A estratégia para distinguir o ser do parecer consiste em mostrar as diferenças entre o filósofo, o sofista e o político. A tentativa de definir o sofista esconde a definição do filósofo. O mesmo se pode dizer do político. Um se mostra "dialeticamente" no outro. Assim, o diálogo Sofista traz no seu desenvolvimento, na oralidade que sustenta as aparentes digressões do texto, os grandes temas do ser e do não-ser; um panorama (mais sistemático do que histórico) das teorias do ser (os pluralistas), (os unitários), (os filhos da terra e os amigos das Formas); os problemas da participação, da predicação e a comunidade dos gêneros supremos; o não-ser e o erro na opinião e no discurso e a conseqüente falibilidade da linguagem.

Se a filosofia não tem a função de estudar os objetos, os "conteúdos" do conhecimento, mas as condições que permitem conhecê-los, ou seja, a forma do conhecimento, pois, sua tarefa consiste, nas palavras de Tugendhat, "em esclarecer pressupostos fundamentais de todo compreender", então, o diálogo Sofista é um texto filosófico que funciona como modelo, tanto sob o ponto de vista dos temas quanto sob o ponto de vista do método de investigação. A história da ciência mostra que muitas questões da filosofia grega foram superadas. Entretanto, os problemas filosóficos de textos, como o Sofista, reatualizados, desafiam até hoje a reflexão filosófica. Platão inaugura, no Sofista, uma sistematização das questões ontológicas tradicionais, mas, ao mesmo tempo, mostra a inseparabilidade do método e do objeto de estudo em filosofia. A reflexão filosófica só pode ser conduzida em conformidade com seus fins quando concomitantemente são questionadas as possibilidades do conhecer e do pensar filosófico. A pretensão de verdade de uma filosofia funda-se no método, isto é, no modo de conhecer e de dizer e na 
medida em que o dizer e o conhecer operam uma referência radical a um sentido de realidade.

' Os resultados da reflexão filosófica confundem-se com o próprio processo de refletir. Esta lição exemplar de o Sofista estende-se aos diálogos do mesmo período ou série lógica como o Parmênides, o Teeteto e o Político. Platão não escreveu 0 diálogo o Filósofo para responder à pergunta "o que é o filósofo?" Todavia, no Sofista e no Político ele mostra como procede um filósofo. O Estrangeiro de Eléia, personagem central dos dois diálogos, é apresentado como um filósofo, um ser divino, um conhecedor do mundo das essências, das Formas, do Uno. Por outro lado, o Estrangeiro ao designar de dialética a ciência que consiste em "dividir por gêneros, e não tomar por outra, uma forma que é a mesma, nem pela mesma uma forma que é outra" (253d), responde a Teeteto com a seguinte indagação: "Por Zeus, não estaremos, sem o sabermos, dirigindo-nos para a ciência dos homens livres e correndo o risco, nós que procuramos o sofista, de haver, antes de encontrá-lo, descoberto o filósofo?" (253cd).

O diálogo o Sofista, enquanto texto filosófico exemplar, contém em forma nuclear os grandes paradigmas da filosofia ocidental, o enfoque ontológico da tradição, a guinada lingüística da modernidade, e, talvez, em escala menor, o início da reflexão transcendental. Isto quer dizer que o texto, ao lado de potencialidades interpretativas que nascem de sua radicalidade como pensamento filosófico, também apresenta limitações específicas, pois, a linguagem de Platão ainda não tem o rigor e a elaboração que a história da filosofia lhe atribui. A filosofia de Platão é anterior às sistematizações e à elaboração das grandes categorias filosóficas da tradição ocidental. Por isso, uma leitura que a essencialize demais é tão ruim quanto uma interpretação incapaz de filosofar a partir dela.

Para se poder demonstrar hoje que a filosofia é uma atividade a priori, uma ciência universal dos primeiros ou últimos princípios, de certo modo independente da experiência, é necessário um constante retorno aos textos da tradição. As pretensões dos que negam os problemas lógico-ontológico-lingǘsticos ou os ignoram, em nome de uma recepção das questões filosóficas, precisam igualmente retornar aos textos fundadores. E esses, via de regra, são tão ricos em sua natureza filosófica que podem dizer, como ensina Merleau-Ponty, aquilo que neles se lhes põe. Qualquer texto é importante sob determinados enfoques. Alguns textos, no entanto, como ocorre com o Sofista, são necessários para entender uma época ou uma concepção filosófica. Daí a dificuldade de resumi-lo. Tal é sua complexidade e poder de articulação que a tentativa de definir o sofista (221c-226a), (incluindo nesse gênero, em certo aspecto, o próprio Sócrates) (226b-231b), permite caracterizar os procedimentos metódicos da verdadeira e da falsa filosofia, os procedimentos do sofista e do filósofo.

Os inúmeros processos envolvidos na arte da contradição, desde a eristica até a divisão, diairesis, servem para esclarecer a verdadeira dialética, a qual tem a função de mostrar a distinção entre o ser e o parecer, problema este que surge do fato de o sofista parecer saber tudo sobre todas as coisas, quando, na realidade, ele se engana e pode mentir. Assim, o problema do enunciado falso, como dizer o que não é, impõe-se, ao mesmo tempo, como um problema lógico e ontológico, 
analítico e dialético. Esgotadas as possibilidades da linguagem em torno do nãoser, contra a tese de Parmênides, só a solução dialética, exemplificada e efetivada nos gêneros supremos, oferece uma saída para explicar o uno e o múltiplo e, conseqüentemente, definir o sofista e o filósofo.

Um texto redigido em forma de diálogo, embora não tão vivo quanto os textos anteriores, antes de tudo, encena o sentido daquilo que é dito. Do significado que nasce da coesão, da coerência e da objetividade do escrito, exige-se que as palavras "sensiveis" possam ser intelegíveis. Exige-se, portanto, do próprio Platão, o filósofo-escritor, que sabe os limites da escrita antes de todos, como ensina no Fedro, que evite erros, equívocos, "idéias-fantasmas". Exige-se que diga apenas o que é. O início de o Sofista, no prólogo, como costumam dizer os comentaristas, são apresentados os personagens. As relações entre os personagem instauram no diálogo o processo de metalinguagem. O texto, com sua oralidade latente, permite uma abordagem de tipo lógico-formal, mas também interpretações que valorizam sua força performativa e sua dimensão pragmática. Todos estes aspectos fornecem ao Sofista a possibilidade de ser dialeticamente interpretado, isto é, o jogo entre o todo e as partes. A leitura do diálogo, além de analisar os enunciados, os processos demonstrativos da diairesis, deverá levar em conta o dito nas entrelinhas e na armação do drama. Tudo é fundamental, até seu começo singelo: "Fiéis ao compromisso de ontem, caro Sócrates, aqui estamos" (216a). Na realidade, o diálogo Teeteto havia concluído com as seguintes palavras: "Agora devo ir ao pórtico para responder à acusação que Meleto levantou contra mim. Amanhã, Teodoro, podemos voltar a encontrar-nos aqui" (210d).

Uma informação sobre um personagem como Sócrates, por exemplo, pode ser importante para entender o diálogo. Os personagens do prólogo, (prólogo, aliás, que vale também para o Político) são Teodoro, o matemático de Cirene, o jovem ateniense Teeteto, também ele matemático. Os dois trazem consigo um estrangeiro desconhecido dos demais, que vem de Eléia, discípulo de Parmênides e de Zenon. O encontro imediatamente é dominado por Sócrates e o Estrangeiro, que permanece sem nome em todo o diálogo. Dele apenas se sabe a origem, a formação. Quanto a Sócrates, (aqui está a importância de certas informações) paciente de um processo de condenação, mostra-se apreensivo com a identidade do estranho. Pergunta a Teodoro, se não havia acaso trazido consigo, não um hóspede, mas um deus, recordando assim os versos da Odisséia de Homero. Sócrates responde a Teodoro: "Ele é mais comedido do que os ardorosos amigos da Erística. Não o vejo como um deus, mas parece-me um ser divino, pois chamo assim a todos os filósofos" (216b).

Nessas poucas palavras, estão presentes questões que merecem atenção especial: a) o filósofo não é um deus, mas um ser divino; b) o estrangeiro, exemplo de filósofo, não é um defensor da erística, da controvérsia pela controvérsia. Tratase, todavia, de uma única questão, poder-se-ia dizer, de verdade e método. Se o deus dos hóspedes, segundo a tradição homérica, vem para punir as más ações dos homens, o Estrangeiro de Eléia, caso fosse um deus, um deus da refutação, poderia ter vindo para refutar os erros dos presentes, inclusive de Sócrates. Mas, nas dobras dessa questão está presente uma outra: como se mostram os filósofos 
aos homens comuns, como é possivel distinguir no filósofo aquilo que ele é e aquilo que ele parece ser. Como distinguir entre o original e a imagem?

Além de Teodoro, Sócrates, o Estrangeiro de Eléia, Teeteto, outros personagens, como o jovem Sócrates, homônimo de Sócrates, estão presentes. Nesse sentido, espera-se que o leitor de o Sofista tome parte do diálogo. A oralidade o exige. Dialética e oralidade relacionam-se naturalmente como análise e escrita. Dialética remete necessariamente à gênese do diálogo. Por isso, o horizonte da oralidade que sustenta 0 diálogo escrito permite um desdobramento dos temas abordados distinto da simples exposição. A intenção temática inicial consiste na caracterização do filósofo para os homens comuns. Uns lhe atribuem valor demasiado, para os outros ele nada vale. Não é fácil determinar o gênero divino do filósofo. Ao juizo ignorante das multidões, ele assume aparências diversas. Para a opinião comum, os filósofos assumem "as formas de políticos, ou de sofistas, e outras vezes, dariam ainda, para certas pessoas, a impressão de estarem completamente em delírio" (216d). O tema geral de o Sofista consiste na tentativa de dizer, positivamente, quem é o sofista para, negativamente, caracterizar o filósofo. O tema transforma-se num problema de investigação radical das relações entre 0 ser e o parecer, entre o mundo inteligivel e o mundo sensivel. O processo dessa investigação, conduzido pelo Estrangeiro de Eléia, mostra o que verdadeiramente faz um filósofo.

Sócrates quer saber como o Estrangeiro, legítimo representante de Parmênides, caracteriza o sofista, o político e o filósofo. Não se trata de definir indivíduos, mas três gêneros considerados distintos. O Estrangeiro, depois de observar as dificuldades dessa tarefa, indagado novamente por Sócrates sobre o método que pretende usar, escolhe o procedimento considerado o mais fácil, aquele com um interlocutor. Ele não aprecia as "disputas verbais". Não quer nem o monólogo puro nem o diálogo. Deixa de lado o método que consiste no desenvolvimento da tese mediante uma longa exposição e o método das perguntas e respostas usado por Parmênides, na sua velhice, na presença do próprio Sócrates, quando este era ainda jovem (217c). Todavia, sem abandonar a exposição e o recurso das perguntas e respostas, o Estrangeiro prefere expor com a mediação de um interlocutor. Escolhe expor para "um outro". E Teeteto é escolhido para exercer este papel. As perguntas e respostas, nesse caso, transformam-se num simples exercício (218b).

O Estrangeiro de Eléia não poderia escolher Sócrates como interlocutor ao usar esse método, seria uma descortesia com quem o recebe. Além disso, os problemas abordados não são da especialidade de Sócrates. Nos diálogos escritos na maturidade de Platão, problemas lógicos e ontológicos, como os apresentados no Parmênides e no Sofista, cosmológicos, como no Timeu e de legislação e jurisprudência, como no Politico e nas Leis, não têm a presença dominante de Sócrates. Sócrates retorna como personagem central no Filebo onde as questões éticas são centrais.

A função pedagógica da filosofia e da dialética está presente. Platão, no Sofista não esgota as possibilidades do método dialético. Realiza apenas uma dialética negativa, dualista, divisionista. Tal procedimento pode ser visto como uma etapa para alcançar a dialética, o processo da síntese. Os gêneros supremos quan- 
do considerados não como uma mera via categorial (no sentido aristotélico) talvez possam efetivar o pensamento dialético explicitado pela Doutrina Não Escrita. O Estrangeiro é apresentado como o praticante da melhor tradição eleática. Portanto, não é um mero refutador, empenhado em simplesmente disputar e apontar os erros do interlocutor, como procediam os sofistas. A definição do sofista, tema de entrada do diálogo, pressupõe o esclarecimento, mediante o discurso, logos, da natureza do sofista. E isto implica a busca de uma concordância sobre o uso do nome, ónoma, da coisa e do discurso. O método da divisão, diairesis, é um processo de investigação, de descoberta e ao mesmo tempo de esclarecimento do conhecimento do objeto, isto é, do gênero sofista. O ponto de partida é o gênero, a unificação, synagogê. A partir do gênero, chega-se por divisão, diairesis, à espécie. O estrangeiro sabe que esse método é insuficiente. Entretanto, é um início, um modo simples de começar. Nessa direção, o exemplo do pescador com linha serve como modelo (218d) para tentar as (sete) definições do sofista. O método da diairesis tem como pressupostos o conhecimento visto como "aquisição", "separação" e "produção. As diversas técnicas de adquirir, separar, produzir exigem regras, estas, no entanto, são apresentadas só no Político. O conhecimento para Platão é apropriação de algo preexistente, da essência, ousia, mesmo quando fala em produção.

O processo diairético no Sofista, sem abandonar as perguntas e respostas, investiga alguns problemas que se entrelaçam. É possivel até observar uma estrutura no texto. Após o prólogo, começa com o exemplo do pescador com linha, para posteriormente aplicar a divisão, diairesis, às seis definições do sofista. Com a revisão das definições do sofista, não como indivíduo, mas como espécie, começa a formular e ao mesmo tempo interrompe a sétima definição (216a-237a). Num segundo momento, destaca as questões do erro e do não-ser, o exame crítico das teorias do ser, a predicação, a participação e comunicação dos gêneros supremos (237a-259d). Num terceiro momento, investiga a possibilidade do erro no discurso e na opinião (259d-264b). Finalmente, apresenta a sétima definição do sofista, ilusionista da palavra, técnico do engano (264b-268d).

Do mesmo modo que é possível analisar o processo diairético do Sofista, considerando o desenvolvimento de seus núcleos problemáticos, também é possivel relacionar este diálogo com os demais, considerando a totalidade da obra de Platão. Vimos como se interliga o final do Teeteto e o início do Sofista. No Teeteto destaca-se a aporia da impossibilidade de fazer ciência a partir da sensação. A crítica de Platão contra as idéias de Protágoras complementam-se com a discussão de Sócrates com Zenão e Parmenênides, no início de o Parmênides, em relação à necessidade de um mundo inteligivel puro, a priori. Sócrates chega a entender tal posição. É natural, portanto, que no Sofista e em outros diálogos de maior alcance teórico deixe lugar ao Estrangeiro para conduzir a conversação. O Sofista é um diálogo escrito certamente para iniciados, pois, se observa nele, por exemplo, a ausência de mitos. Por outro lado, enquanto no Crátilo o dialético preside a análise e a composição dos nomes, no Sofista o dialético preside a análise e a composição das definições. Na Crátilo exige-se impossibilidade do erro. No Sofista ocorre a demonstração da possibilidade do erro. No Crátilo aparece a relação e convenção 
entre os falantes. No Sofista a relação como comunidade de gêneros. No Crátilo, Platão comete o parricídio de Heráclito. No Sofista, o parricídio de Parmênides. Ainda em relação a outros diálogos, no Sofista como na Republica surge o problema das imagens, da cópia e do simulacro. Enfim, o exercício de comparação entre os diálogos é útil para elucidar problemas específicos.

Ao tentar definir o sofista e o político, Platão mostra a natureza do filósofo. Não é fácil saber quem é o filósofo. A tarefa exige a distinção entre o ser e o parecer, entre o original e a imagem. Aos olhos do cidadão comum o filósofo parece ser um político, sofista ou louco. É o dom dialético que caracteriza o filósofo (253e). O método permite formular as distinções entre o ser e o parecer e esclarece a "obscuridade do não-ser" e do dizer falso.

\section{Referências bibliográficas}

CORNFORD, F. M. La teona platónica del conocimiento. Buenos Aires: Paidos, 1991.

MOVIA, G. Apparenze, essere e verità, commentario storico-filosofico al "Sofista" di Platone. Milano: Vita e Pensiero, 1991.

PLATÃO. Diálogos: O Banquete, Fédon, Sofista, Político. São Paulo: Abril Cultura, 1972.

PLATON. Oeuvres complètes, Le Sophiste. Texto bilingüe, trad. Para o francês de Auguste Diès. Paris: Les Belles Lettres, 1963.

ROSEN, S. Plato's Sophist, The drama of original and image. New Halen and London: Yale University Press, 1983. 